\title{
MANEJO DE RECURSOS LÍTICOS EN LA CUENCA DEL LAGO SALITROSO (SANTA CRUZ)
}

\section{LITHIC RESOURCES MANAGEMENT IN LAKE SALITROSO BASIN (SANTA CRUZ)}

\author{
Gisela Cassiodoro \\ CONICET-UBA-INAPL. 3 de Febrero 1378, Ciudad Autónoma de Buenos Aires (1426). \\ E-mail: gcassio@hotmail.com
}

Presentado el: 12/09/2013 - Aceptado 29/09/2014

\section{Resumen}

Este trabajo busca ahondar en las características de la utilización de las materias primas líticas efectuadas en la cuenca del lago Salitroso (Santa Cruz). A tal fin, se presenta información sobre los artefactos formatizados, desechos de talla y núcleos de los conjuntos de superficie. Se registra una planificación en las actividades relacionadas con el abastecimiento, uso y selección de recursos minerales necesarios para la producción de las diferentes tecnofacturas. Al mismo tiempo, dado que se ha propuesto que dicha cuenca habría sido utilizada de manera permanente y semi-permanente de forma residencial por grupos cazadores- recolectores durante el Holoceno tardio, se espera aportar información a la discusión sobre el uso y manejo de los recursos líticos en contextos de movilidad residencial reducida.

Palabras claves: Materias primas, Movilidad, Holoceno tardío.

\begin{abstract}
This work looks forward to examine in great detail the lithic raw material use at lake Salitroso basin (Santa Cruz). To do so, information from tools, debitage and cores is presented. It is show a planification in the activities related with supply, use and selection of lithic resources needed in stone production. At the same time, because this basin had been proposed with a semipermanent residential use by hunter gatherers during late Holocene, we expect to bring information to the discussion of the use and management of lithic resources in contexts with low residencial movements.
\end{abstract}

Key words: Raw material, Mobility, Late Holocene 


\section{Introducción}

La cuenca de los lagos Salitroso-Posadas-Pueyrredón se encuentra en el noroeste de la provincia de Santa Cruz en un ambiente de estepa arbustiva, a una altura promedio de $200 \mathrm{msnm}$ y presenta una buena disponibilidad de diferentes recursos (agua, leña, reparo, recursos animales y minerales) (Figura 1). En el marco del modelo de poblamiento propuesto para la cuenca (Goñi 2000, 2010; Goñi et al. 2000-2002) se ha planteado que bajo condiciones de una progresiva, aunque fluctuante, desecación ambiental que habría comenzado hacia los 2.500 años AP (Stine y Stine 1990) e intensificado hacia los 900 años AP (Stine 1994), la misma se habría convertido en un espacio privilegiado para la ocupación humana y serían potencialmente utilizable durante todo el año, llevando a la reducción de la movilidad residencial de los grupos cazadores- recolectores (Goñi 2000). Este proceso, ausente en momentos previos, habría llevado al nucleamiento de poblaciones en determinados sectores ambientales, a partir de los cuales se desarrollarían movimientos logísticos y estacionales hacia otros sectores para la obtención de recursos específicos, como cuencas lacustres altas o mesetas (Goñi 2000, 2010).

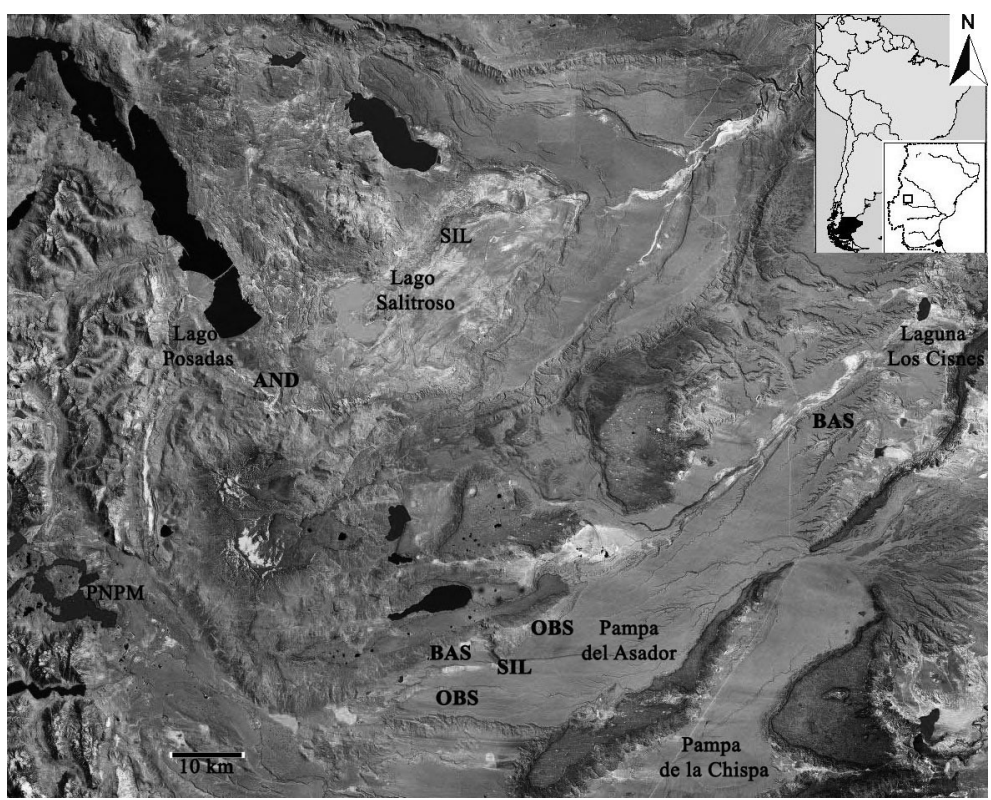

Figura 1. Mapa del área y localización de materias primas líticas. Referencias: OBS: obsidiana, SIL: rocas silíceas, BAS: Basalto, AND: Andesita

En la cuenca del lago Salitroso se ha determinado la existencia de una alta frecuencia de entierros humanos en chenques, nichos y entierros bajo bloque (García Guráieb et al. 2007a) Al mismo tiempo, existen conjuntos artefactuales registrados tanto en concentraciones como de manera aislada en superficie (Cassiodoro 2008). Así, se han relevado 19 concentraciones de material lítico, cerámico y óseo. Los fechados radiocarbónicos obtenidos sitúan a las ocupaciones humanas en un período climático seco del Holoceno tardío (Cassiodoro et al. 2004a; Cassiodoro y García Guráieb 2009; García Guráieb et al. 2007a, 2007b; Goñi 2000-2002; Goñi et al. 2000-2002) dado que las concentraciones de superficie van desde $1.600 \pm 110$ años AP (AC1687 carbón) a $750 \pm 60$ años AP (UGA8707 carbón) y los enterratorios van desde $2.607 \pm 41$ años AP (AA38568 hueso) a $352 \pm 40$ años AP (AA38555 hueso). Esto es concor- 
dante con los relevamientos sedimentológicos realizados por Horta que han determinado la existencia de un gran lago que conectaría a los lagos Salitroso, Posadas y Pueyrredón. Se infiere que esta conexión abarcaría el lapso entre 11.000 años AP y 2.500 años AP (Horta y Aschero 2010), evidenciando la efectiva disponibilidad de los espacios en estudio hacia el Holoceno tardío. Esto permite acotar temporalmente a los materiales líticos de superficie que serán abordados en este trabajo.

Considerando que la tecnología debería reflejar los cambios mencionados, las investigaciones tecnológicas del área buscan explicar cuáles serían las características de la utilización de distintos ambientes bajo condiciones ambientales específicas y cuáles serían sus implicancias tecnológicas. En particular, cuáles serían los aspectos tecnológicos desarrollados en momentos donde, por distintos factores, la movilidad residencial de los grupos se vería reducida (Cassiodoro 2008). En el marco del proceso de poblamiento tardío propuesto para el área de estudio (Goñi 2000; Goñi et al. 2000-2002), se busca explicar la variabilidad tecnológica, considerando los aspectos organizativos de los grupos cazadores- recolectores, para abordar la movilidad de los mismos.

En particular, el objetivo general de este trabajo es establecer las características del aprovisionamiento y utilización de las materias primas líticas en la cuenca del lago Salitroso. Anteriormente, se ha planteado que la distancia a la fuente de abastecimiento afecta de forma diferencial la frecuencia de las materias primas en los conjuntos de los distintos sectores de la cuenca de los lagos Salitroso-Posadas-Pueyrredón (Cassiodoro et al. 2004b). A su vez, se ha propuesto que el desarrollo de distintas actividades segregadas espacialmente en estos sectores podría estar incidiendo en la representación de las materias primas líticas en el registro arqueológico. Al profundizar el análisis de los conjuntos de uno de dichos sectores- cuenca del lago Salitroso- se busca establecer de qué manera ésto podría estar operando en una escala espacial menor. Para lo cual, por un lado, se dará una aproximación a la variabilidad entre las 19 concentraciones artefactuales y por otro, las mismas se abordarán conjuntamente para caracterizar el manejo de los recursos líticos de la cuenca.

Así, se plantea como hipótesis que las características de los conjuntos tecnológicos estarán condicionadas por el carácter residencial y la mayor duración de las ocupaciones en las cuencas lacustres bajas, en un contexto de reducción de la movilidad durante el Holoceno tardío. Se propone que para una mejor utilización de los espacios se habrían tomado decisiones específicas para el manejo de sus recursos, implicando el desarrollo de estrategias tecnológicas vinculadas con una mayor planificación de las actividades, en particular las relacionadas con la obtención y procesamiento de recursos faunísticos y el aprovisionamiento y uso de los recursos líticos.

\section{Abordaje teórico-metodológico}

Las consideraciones teórica qua guían estas investigaciones han sido desarrolladas en otras oportunidades (Cassiodoro et al. 2004b; Cassiodoro 2008; Guráieb et al. 2006). A modo de síntesis, la tecnología es abordada desde la propuesta de la organización tecnológica (Nelson 1991) y se considera que la frecuencia en que determinada materia prima se encuentra en el registro arqueológico está condicionada por su disponibilidad, en la cual inciden factores no sólo naturales sino también organizativos de los grupos (Bamforth 1986; Bousman 1993; entre otros). 
En este trabajo se tomará la información proveniente de 19 conjuntos de superficie del área. La caracterización geomorfológica y arqueológica de los mismos ha sido especificada en otras publicaciones y se ha evidenciado el desarrollo de un amplio rango de actividades en la mayoría de las concentraciones artefactuales (Aragone et al. 2004; Cassiodoro et al. 2004a; Cassiodoro 2010; Goñi et al. 2000-2002).

El manejo de los recursos líticos será abordado en relación con los artefactos formatizados, los desechos de talla y los núcleos, utilizando la tipología propuesta por Aschero (1975, 1983). Para el análisis de los desechos de talla también se tuvo en cuenta lo propuesto por Bellelli y colaboradores (1985-1987). Se consideraron atributos referidos a la composición técnica y tipológica de los conjuntos (clase de artefacto, estado, materia prima, tamaños, forma base) y de la formatización (cantidad de filos). Mediante el establecimiento de relaciones entre los distintos atributos y variables se buscó señalar las propiedades que caracterizarían la utilización y aprovisionamiento de materia prima en la cuenca, considerando conjuntamente a las concentraciones. En este trabajo para evaluar la variabilidad entre conjuntos sólo se tomó en cuenta la frecuencia de materias primas en los distintos artefactos utilizando análisis de correspondencia.

La determinación de los tipos de rocas utilizados para la confección de artefactos fue realizada de manera macroscópica. Para la caracterización de algunas de ellas se efectuaron consultas a otros investigadores del tema en el área y se buscó delinear categorías amplias. De esta manera, materias primas como el xilópalo, ópalo y calcedonia fueron incluidas dentro de las rocas silíceas. Una serie de materias primas indeterminadas de origen volcánico y materias primas representadas en muy baja frecuencia han sido englobas en la categoría de otras.

\section{Fuentes de aprovisionamiento}

Necesariamente, para entender la procuración de las materias primas es fundamental establecer la estructura de la base regional de recursos minerales (Ericson 1984). Esto implica dar cuenta de la localización y la forma en que se presentan en la naturaleza las distintas materias primas. El establecimiento de los puntos o sectores del espacio en que se encuentran disponibles estos recursos permite evaluar las posibilidades de acceso a los mismos por parte de los grupos cazadores- recolectores y los resultantes patrones y vías de circulación humana.

Las rocas más representadas en el registro lítico de la cuenca son la andesita o basalto Posadas, la obsidiana y distintas variedades de rocas silíceas. En menor frecuencia aparecen la riolita y otras litologías como cuarcita, limolita, tobas silicificadas, dacita y variedades de rocas volcánicas y sedimentarias no diferenciadas. Debido a la intensa acción glaci-fluvial que modeló el paisaje, principalmente durante el Pleistoceno y comienzos del Holoceno, las fuentes de aprovisionamiento de la mayoría de las materias primas presentes en el registro son de tipo secundario (Nami 1992). Un análisis detallado de las fuentes de aprovisionamiento de la cuenca de los lagos Salitroso- Posadas- Pueyrredón ha sido presentado anteriormente (Cassiodoro et al. 2004b; Guráieb 1998).

Resumiendo esta información, se puede decir que el basalto denominado "Posadas" y caracterizado geoquímicamente como andesita (Guráieb 2012) se encuentra en las terrazas fluviales y en el abanico aluvial del río Tarde, a unos $20 \mathrm{~km}$ al sudoeste del lago Salitroso. Se 
presenta en la forma de bloques angulosos de tamaños medianos y grandes. También se han registrado guijarros con características macroscópicas similares en Pampa del Asador a 45 $\mathrm{km}$ hacia el sureste de la cuenca (Figura 1). En este sector también se encuentra en forma de guijarros otra variedad de basalto de muy buena calidad para la talla (Espinosa y Goñi 1999).

La obsidiana negra proviene de la fuente secundaria localizada en Pampa del Asador y se presenta en forma de guijarros y rodados que pueden llegar a $15 \mathrm{~cm}$ de diámetro (Espinosa y Goñi 1999; Stern 1999). También han sido registrados nódulos de menor tamaño hacia el este de Pampa del Asador (Belardi et al. 2006).

Hasta el momento, para la mayoría de las variedades de rocas silíceas no se han ubicado fuentes de aprovisionamiento en la cuenca. La excepción está dada por una variedad de sílices gris-verdosa y amarillenta, cuya fuente de aprovisionamiento primario se localiza al norte del lago Posadas (Guráieb 1998, 2000). A su vez, algunas variedades han sido localizadas en las cercanías de los cursos de agua en forma de rodados pequeños y medianos (entre 5 y $10 \mathrm{~cm}$ de diámetro aproximadamente). Por otra parte, en Pampa del Asador también fueron identificados nódulos de distintos tamaños y variedades de rocas silíceas de muy buena calidad (Espinosa y Goñi 1999). Recientemente, se han registrado guijarros y bloques de buena calidad en las inmediaciones de la laguna Los Cisnes, aproximadamente a unos $75 \mathrm{~km}$ al este de la cuenca (Aschero et al. 2010).

\section{Presentación de la información}

Artefactos formatizados

Las principales materias primas representadas en los artefactos formatizados son obsidiana, distintas variedades de rocas silíceas y basalto Posadas o andesita. La obsidiana $(32,59 \%)$ y las rocas silíceas $(32,34 \%)$ son las que se encuentran en mayor frecuencia y con valores muy similares (Figura 2). Los artefactos formatizados se encuentran fracturados en la mayoría de las materias primas (Figura 2). No obstante, si no consideramos la categoría "otras", la obsidiana presenta los porcentajes mayores de piezas enteras, seguida por las rocas silíceas.

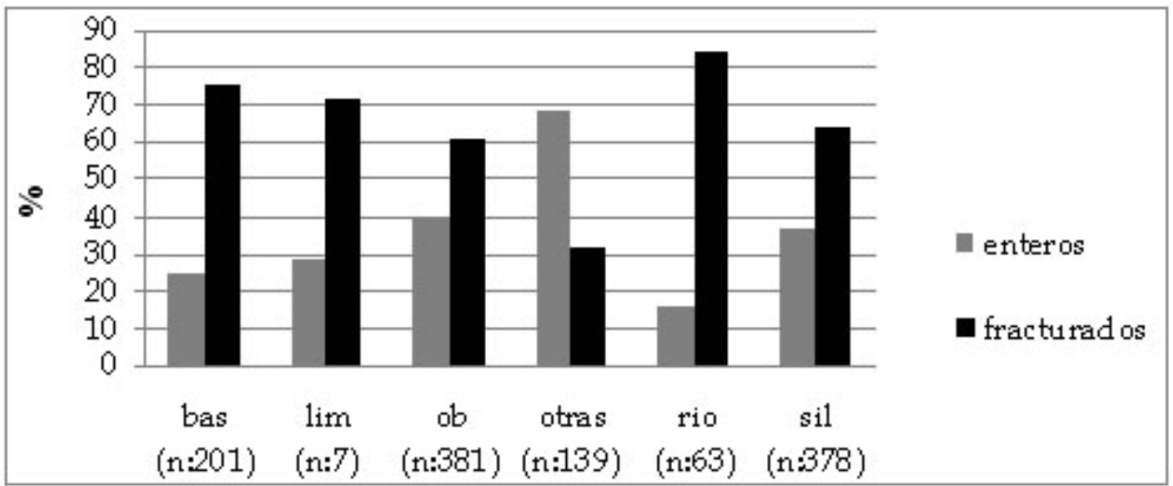

Figura 2. Estado artefactos formatizados (n: 1169). Referencias: bas.: basalto, lim.: limolita, ob.: obsidiana, rio.: riolita, sil.: sílice. 


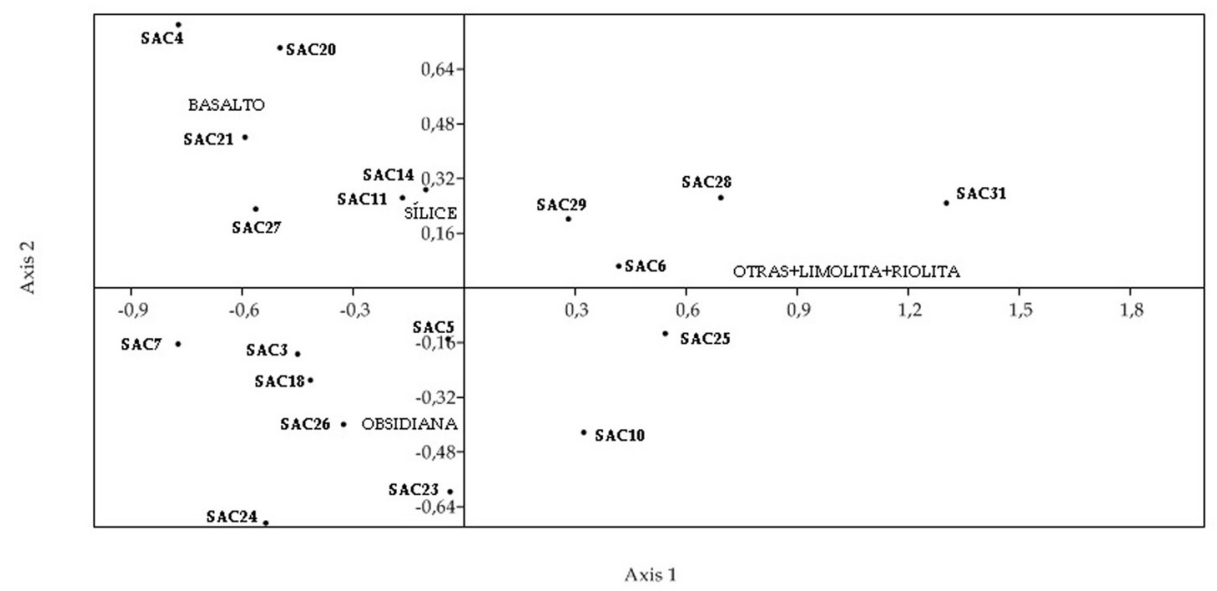

Figura 3. Análisis de correspondencia artefactos formatizados (eje 1: 56,5\% eje 2: 29,8\%)

En la figura 3 se observan diferencias entre las concentraciones artefactuales que son estadísticamente significativas ( $\mathrm{chi}^{2}=159,67 \mathrm{gl}=54$ valor $\left.\mathrm{p}=<0,001\right)$. Así, existen conjuntos caracterizados por la obsidiana (SAC 3, SAC 7, SAC 10, SAC 18, SAC 23, SAC 24 y SAC 26), mientras que otros por la mayor frecuencia de rocas silíceas (SAC 5, SAC 11 y SAC 29). Se destaca que SAC 4 es el único conjunto donde es mayor el número de artefactos enteros en basalto/ andesita. Es de resaltar que en algunas de las concentraciones (SAC 6, SAC 25 y SAC 31) las materias primas más representadas son las incluidas en la categoría de otras, esto está en relación con la alta frecuencia de artefactos de molienda en ellas (Cassiodoro 2010).

En líneas generales, tanto la obsidiana como las rocas silíceas son las materias primas principalmente seleccionadas para la manufactura de artefactos formatizados en la cuenca del lago Salitroso. Sin embargo, la presencia de diferencias entre las concentraciones artefactuales con respecto a las materias primas más frecuentes da cuenta de una variabilidad interna en su utilización en los distintos sectores de la cuenca. Esta variabilidad también ha sido registrada en torno a la estructura artefactual de cada uno de ellos (Cassiodoro 2010).

Tomando conjuntamente las 19 concentraciones artefactuales, se registra una selección de determinadas materias primas para la manufactura específica de algunas clases artefactuales. En la figura 4, sólo se especificaron los artefactos manufacturados por talla ya que los realizados por picado, pulido y / o abrasión fueron confeccionados en materias primas englobadas en la categoría "otras" (Cassiodoro 2010). Así, se observa que las puntas de proyectil son, fundamentalmente, de obsidiana y las raederas de basalto/ andesita. En el caso de los raspadores, predominan los manufacturados en rocas silíceas aunque se destaca también la utilización de la obsidiana. En menor frecuencia, las rocas silíceas también han sido seleccionadas para la manufactura de perforadores, cuchillos y bifaces. Se destaca la alta frecuencia de artefactos de formatización sumaria y filos naturales con rastros complementarios en obsidiana. 


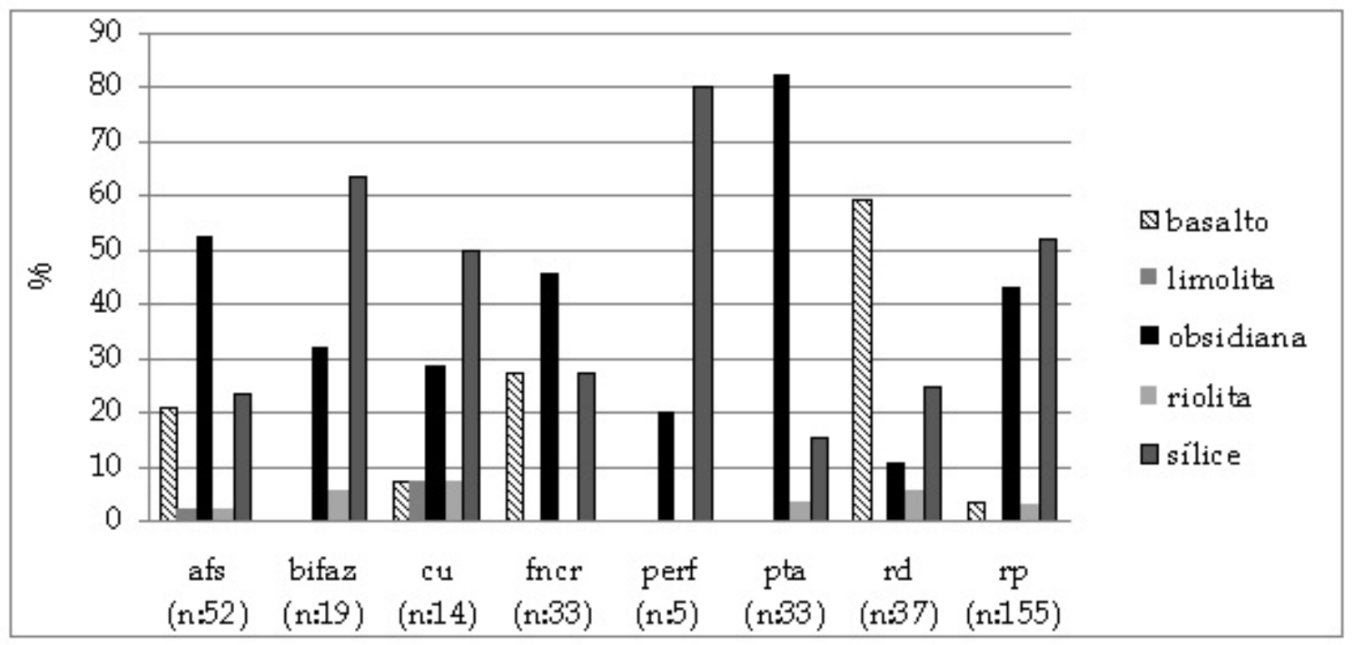

Figura 4. Tipo de artefacto formatizado entero por materia prima. Referencias: afs: artefactos de formatización sumaria, bif.: bifaz, cu: cuchillo, fncr: filo natural con rastros complementarios, perf.: perforador, pta.: punta de proyectil, rd.: raedera, rp.: raspador.

Con respecto a los tamaños de los artefactos formatizados por talla que se encuentran enteros se evidencia variabilidad entre las materias primas (Figura 5). Así, en obsidiana predominan ampliamente los tamaños medianos pequeños y en las rocas silíceas prevalecen los medianos pequeños y medianos grandes, estando representadas todas las categorías de tamaños. Por su parte, en el basalto/ andesita están en mayor frecuencia los tamaños mayores (grande y muy grande).

Si se considera la materia prima de las correspondientes formas base (Tabla 1), se observa que las lascas internas (principalmente, lascas angulares y de arista) se encuentran en porcentajes mayores en todas las materias primas. No obstante, puede destacarse la mayor representación en obsidiana de las lascas externas. Aunque están en bajas frecuencias, formas base que tienden a relacionares con estrategias que buscan maximizar la utilización de las materias primas como, lascas de reactivación de núcleo y hojas, están en porcentajes mayores en el basalto y las rocas silíceas.

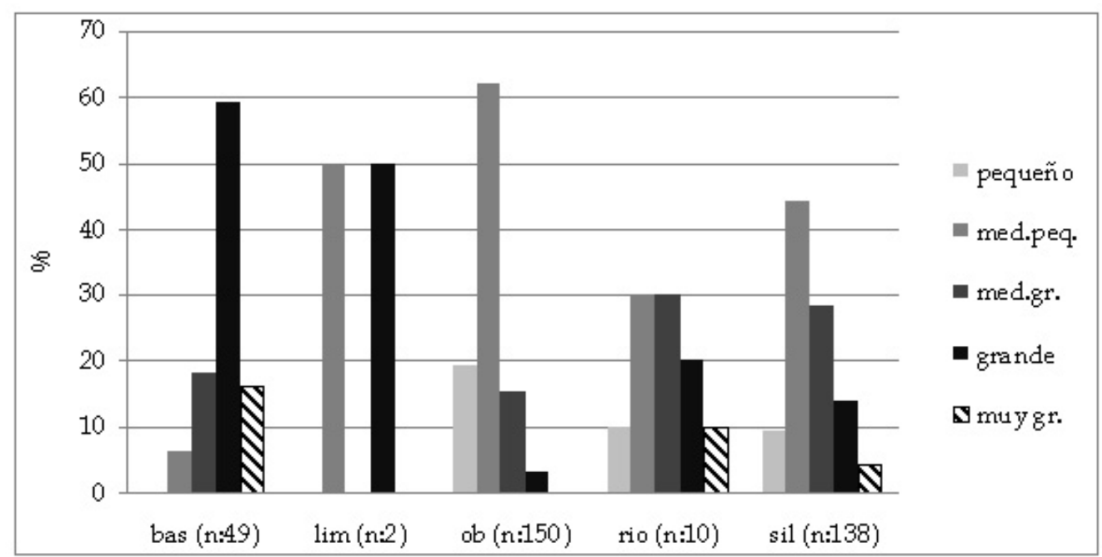

Figura 5. Tamaños y materias primas de artefactos formatizadosReferencias: bas.: basalto, lim.: limolita, ob.: obsidiana, rio.: riolita, sil.: sílice, peq.: pequeño, med.: mediano, gr.: grande 


\begin{tabular}{|c|c|c|c|c|c|c|}
\hline forma base & basalto & limolita & obsidiana & riolita & silice & total \\
\hline 1s.int. & 55,1 & 100 & 36 & 30 & 58,69 & 47,85 \\
\hline 1s.ext & 18,36 & - & 30 & 20 & 15,2 & 22,06 \\
\hline bifaz & 2,04 & - & 0,67 & - & 0,72 & 0,86 \\
\hline hoja & 8,16 & - & 2 & 10 & 4,35 & 4,01 \\
\hline indi. & - & - & 22,67 & 20 & 10,14 & 14,33 \\
\hline inst.indi. & - & - & 1,33 & - & 0,72 & 0,86 \\
\hline 1s . laminar & 2,04 & - & 1,33 & - & 0,72 & 1,15 \\
\hline 1s.in. & 10,2 & - & 5,33 & 10 & 5,8 & 6,3 \\
\hline 1s.r.n. & 4,08 & - & 0,67 & 10 & 2,89 & 2,29 \\
\hline núcleo & - & - & - & - & 0,72 & 0,29 \\
\hline total & $100(\mathrm{n}: 49)$ & $100(\mathrm{n}: 2)$ & $100(\mathrm{n}: 150)$ & $100(\mathrm{n}: 10)$ & $100(\mathrm{n}: 138)$ & $100(\mathrm{n}: 349)$ \\
\hline
\end{tabular}

Tabla 1. Porcentaje de formas base por materias primas Referencias: indi: indiferenciado, ls. int: lascas internas (lasca angular, de arista y plana) ls. ext: lascas externas (lasca de dorso natural, primaria y secundaria) ls.r.n.: lasca de reactivación de núcleo, inst: instrumento

Con el fin de dar cuenta del grado de formatización de los artefactos se registró la cantidad de filos complementarios presentes en los raspadores, dada su mayor representación en todos los conjuntos. Se asume que un mayor número de filos se relaciona con un mayor grado de formatización de los artefactos y una maximización en la utilización de las materias primas (Kuhn 1995). El número de filos complementarios incluye, por un lado, artefactos cuyos diseños tengan más de un filo activo y por otro lado, artefactos que presentan retoques relacionados, posiblemente, con el enmangue de la pieza (aunque no son técnicamente filos). En este caso, la existencia de retoques laterales puede funcionar como una manera de evitar la fractura de los tientos vinculados con el enmangue (Guráieb 2012). En la cuenca, un $58,71 \%$ de los raspadores enteros presentan filos complementarios. En las rocas silíceas los raspadores tienden a presentar más cantidad de filos complementarios que en el resto de las materias primas (Tabla 2), por lo que una mayor formatización puede relacionarse más con este recurso lítico.

\begin{tabular}{|c|c|c|c|c|c|}
\hline filos & basalto & obsidiana & riolita & sílice & total \\
\hline 0 & 40 & 50 & 75 & 35 & 42,58 \\
\hline 1 & 40 & 33,33 & 25 & 37,5 & 35,48 \\
\hline 2 & 20 & 15,15 & - & 26,25 & 20,65 \\
\hline 3 & - & 1,51 & - & 1,25 & 1,29 \\
\hline tota1 & $100(\mathrm{n}: 5)$ & $100(\mathrm{n}: 66)$ & $100(\mathrm{n}: 4)$ & $100(\mathrm{n}: 80)$ & $100(\mathrm{n}: 155)$ \\
\hline
\end{tabular}

Tabla 2. Porcentaje de la cantidad de filos complementarios por materia prima en raspadores

Resumiendo, se destaca la variabilidad en las materias primas utilizadas para la producción de artefactos formatizados, siendo tanto la obsidiana como las rocas silíceas las escogidas en mayor frecuencia. A su vez, se observa la existencia de una selección de materias primas para la confección de determinados artefactos. Asimismo, se registran algunas diferencias en la utilización de los recursos líticos. En obsidiana existe una mayor frecuencia de artefactos formatizados enteros, formas bases en lascas externas y tamaños menores. Las rocas silíceas tienen una alta representación en la cuenca, están en una mayor variedad de tamaños y los raspadores tienen un mayor número de filos complementarios. Los artefactos formatizados en basalto/andesita tienen tamaños mayores, están más fracturados que los manufacturados en rocas silíceas y obsidiana y utilizan una menor variedad de formas base. 
Desechos de talla

En los desechos de talla, la obsidiana es la materia prima que está en mayor frecuencia $(43,9 \%)$, seguida por el basalto/andesita $(25,3 \%)$ y las rocas silíceas $(23,6 \%)$ con valores similares. A pesar que existe una alta representación de los desechos de talla con fractura, debe destacarse que los enteros tienen valores superiores al $30 \%$ en todas las materias primas. Al sumarle a ellos los desechos fracturados que presentan el talón se garantiza la confiabilidad de la muestra (Figura 6).

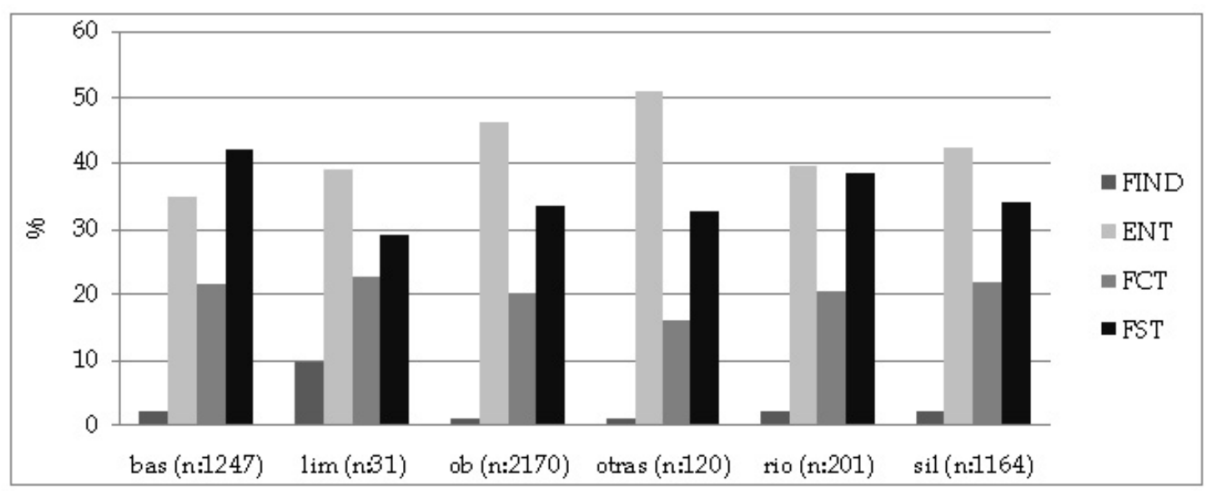

Figura 6. Estado desechos de talla (n: 4933). Referencias: bas.: basalto, lim.: limolita, ob.: obsidiana, rio.: riolita, sil.: sílice, find.: fragmento indiferenciado, ent.: entero, fct; fracturado con talón, fst.: fracturado sin talón.

Al igual que lo observado en los artefactos formatizados, existen diferencias entre las concentraciones artefactuales con respecto a las materias primas (Figura 7), que resultan estadísticamente significativas $\left(\mathrm{chi}^{2}=815,18 \mathrm{gl}=54\right.$ valor $\left.\mathrm{p}=<0,001\right)$. Así, en concentraciones artefactuales como SAC 11, SAC 14, SAC 27 y SAC 4, predominan los desechos de basalto, en SAC 7 y SAC 10 los de sílice y en las restantes los de obsidiana.

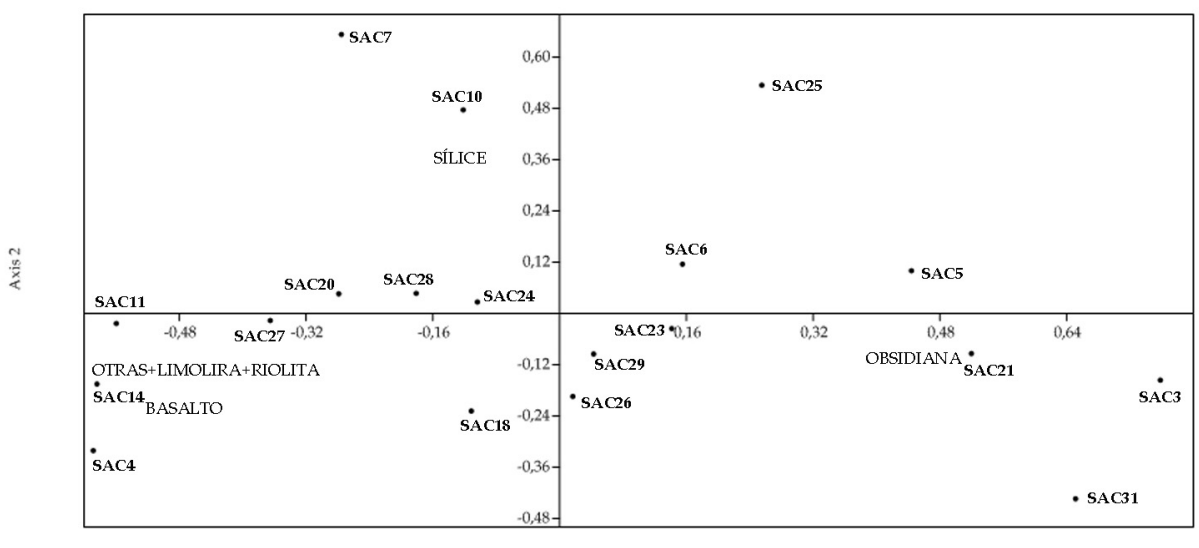

Axis 1

Figura 7. Análisis de correspondencia de desechos de talla enteros y fracturados con talón (eje 1: 76,1\% eje 2: 14,5\%). 
Asimismo, deben mencionarse las diferencias en la representación de materias primas entre artefactos formatizados y desechos de talla. La mayor proporción de artefactos formatizados que desechos de talla en rocas silíceas (0,19 artefactos formatizados por desechos de talla) podría dar cuenta de una mayor entrada de piezas ya manufacturadas a las concentraciones en esta materia prima en comparación con la obsidiana $(0,10)$ y el basalto/andesita $(0,07)$.

Con respecto a los diferentes tipos de desechos de talla (Tabla 3) la tendencia es similar en todas las materias primas ya que predominan ampliamente las lascas internas (lascas angulares, de arista y planas). Sin embargo, la obsidiana y en menor medida el basalto/ andesita tienden a tener porcentajes mayores de lascas externas (lascas de dorso natural, lascas secundarias y lascas primarias, lascas nodulares). Por otra parte, en las rocas silíceas los porcentajes de lascas internas son mayores y tienen una mayor representación de hojas y lascas de reactivación de núcleos.

\begin{tabular}{|c|c|c|c|c|c|c|c|}
\hline tipos & basalto & limolita & obsidiana & otras & riolita & sílice & tota1 \\
\hline 1s.int. & 69,85 & 68,42 & 66,52 & 62,5 & 70,83 & 81,36 & 70,93 \\
\hline 1s.ext. & 22,42 & 15,89 & 24,15 & 25 & 18,33 & 8,31 & 19,69 \\
\hline hoja & 0,71 & 5,26 & 1,4 & - & 0,83 & 2,55 & 1,49 \\
\hline 1s.laminar & - & - & 0,9 & 1,25 & 0,83 & 0,26 & 0,54 \\
\hline indi & 0,86 & - & 0,7 & - & - & - & 0,52 \\
\hline 1s.in & 3,29 & - & 1,96 & 11,25 & 5,83 & 2,28 & 2,72 \\
\hline 1s.r.n & 2,14 & 5,26 & 1,4 & - & 1.6 & 3.08 & 1,97 \\
\hline 1s.ab & 0,43 & - & 0,7 & - & 0,83 & 1,61 & 0,84 \\
\hline 1s.r.ins & 0,29 & 5,26 & 2,2 & - & 0,83 & - & 1,29 \\
\hline total & $100(\mathrm{n}: 700)$ & $100(\mathrm{n}: 19)$ & $100(\mathrm{n}: 1428)$ & $100(\mathrm{n}: 80)$ & $100(\mathrm{n}: 120)$ & $100(\mathrm{n}: 746)$ & $100(\mathrm{n}: 3093)$ \\
\hline
\end{tabular}

Tabla 3. Porcentajes de tipos de desechos de talla y materias primas. Referencias: indi: indiferenciado, ls. int: lascas internas, ls. ext: lascas externas, ls.r.n.: lasca de reactivación de núcleo, ls.ab: lasca de adelgazamiento bifacial, ls.r.ins: lasca de reactivación de instrumentos.

Los desechos de talla enteros tienden a los tamaños pequeños y medianos pequeños en todas las materias primas, aunque se observan diferencias entre ellas (Figura 8). Los desechos de talla de basalto/ andesita están en todas las categorías de tamaños y existe una mayor representación de tamaños mayores. Por su parte, los desechos de obsidiana se encuentran de manera más frecuente en tamaños menores mientras que los desechos de rocas silíceas presentan un patrón intermedio al observado para el basalto y la obsidiana.

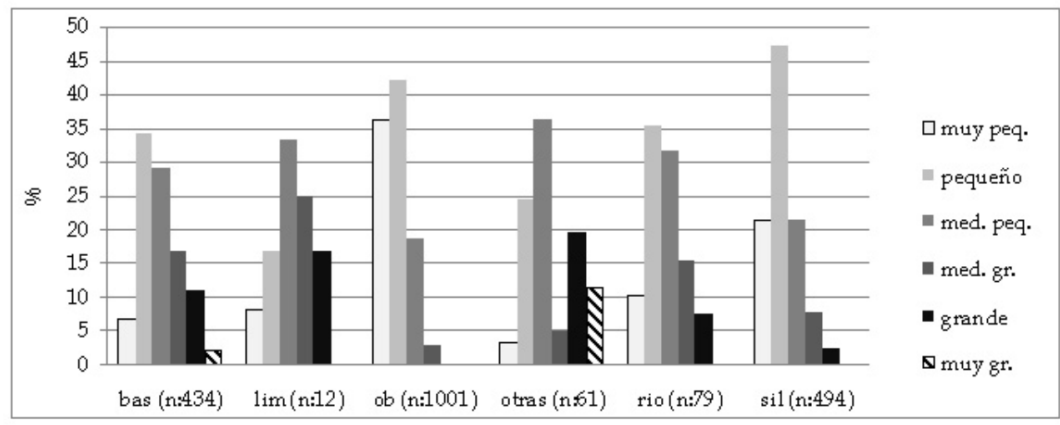

Figura 8. Tamaño y materia prima de desechos de talla enteros. Referencias: med.: mediano, peq.: pequeño, gr.: grande, bas.: basalto, lim.: limolita, ob.: obsidiana, rio.: riolita, sil.: sílice 
En líneas generales, hay una variedad de tipos y tamaños de desechos de talla en todas las materias primas, dando cuenta de la representación de todas las etapas de manufactura de artefactos en la cuenca del lago Salitroso. No obstante, la relación entre artefactos formatizados y desechos de talla y la menor frecuencia de lascas externas en rocas silíceas podría apuntar a un menor desarrollo de las primeras etapas de producción en este recurso lítico.

Núcleos

Los núcleos se encuentran en todas las materias primas, encontrándose en porcentajes similares en las rocas silíceas $(40 \%)$ y la obsidiana $(41,1 \%)$. En el conjunto general predominan las piezas enteras (Figura 9). Sin embargo, es destacar que en las rocas silíceas hay una mayor frecuencia de núcleos fracturados. Dado que, en función de su mayor volumen, es más difícil que la fractura de un núcleo se produzca por procesos postdepositacionales, en este caso la fractura puede estar más relacionada con aspectos comportamentales (por ejemplo, reactivación).

Los núcleos están presentes en todos los conjuntos, con excepción de SAC 7. También se han registrado diferencias entre las concentraciones artefactuales (chi 2 93,17 gl= 51 valor $\mathrm{p}=0,00028$ ) ya que los núcleos de obsidiana se encuentran más representados en las concentraciones SAC 3, SAC 5, SAC 6, SAC 10, SAC 24 y SAC 27; los de basalto en SAC 26 y SAC 29 y los de sílice en SAC 4, SAC 11, SAC 14, SAC 18, SAC 23, SAC 26 y SAC 28 (Figura 10).

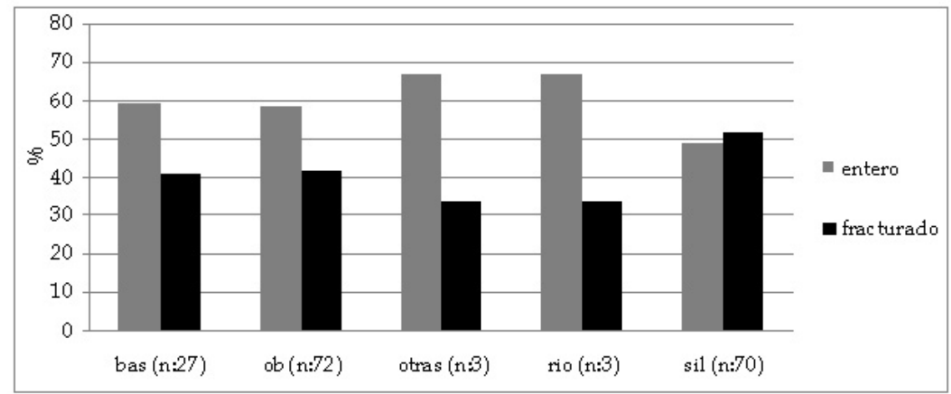

Figura 9. Estado de núcleos. Referencias: bas.: basalto, ob.: obsidiana, rio.: riolita, sil.: sílice

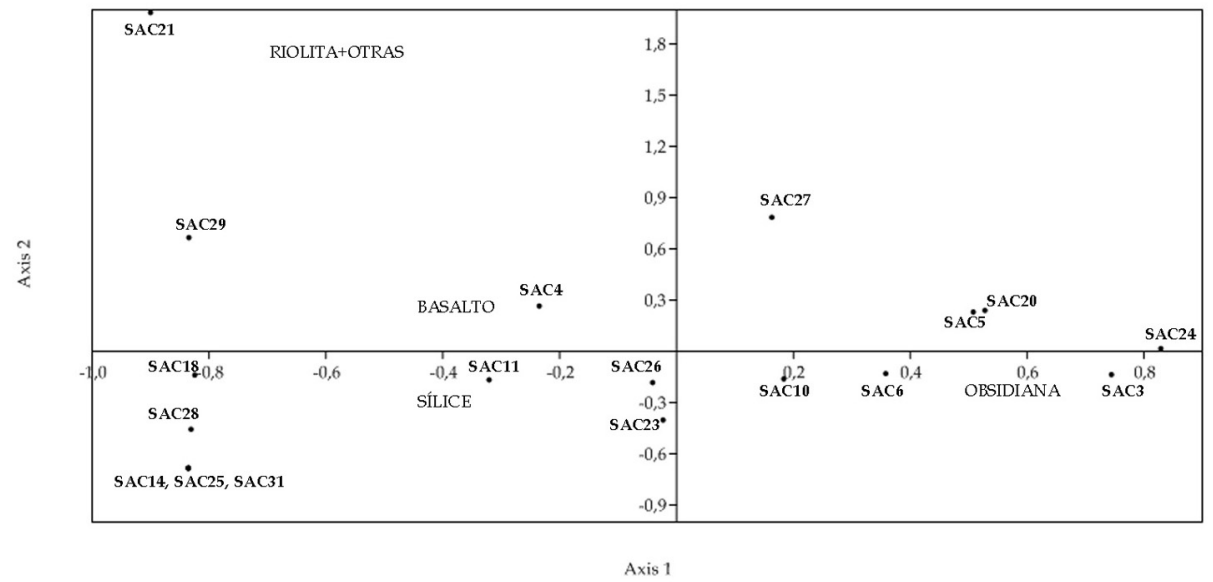

Figura 10. Análisis de correspondencia de núcleos (eje 1: 49,7\%, eje 2: 28,2\%). 


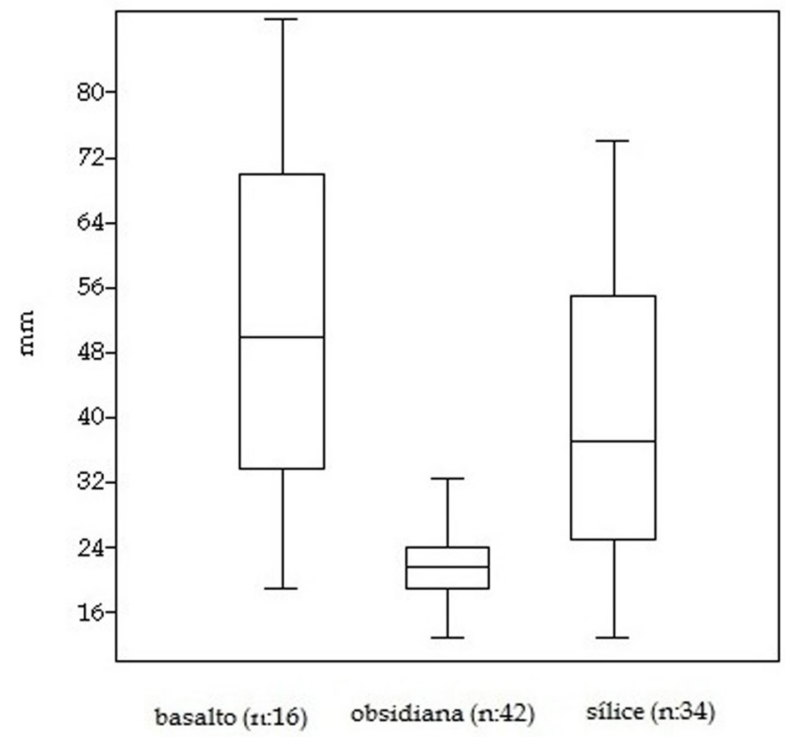

Figura 11. Tamaños y materias primas de núcleos enteros (mm).

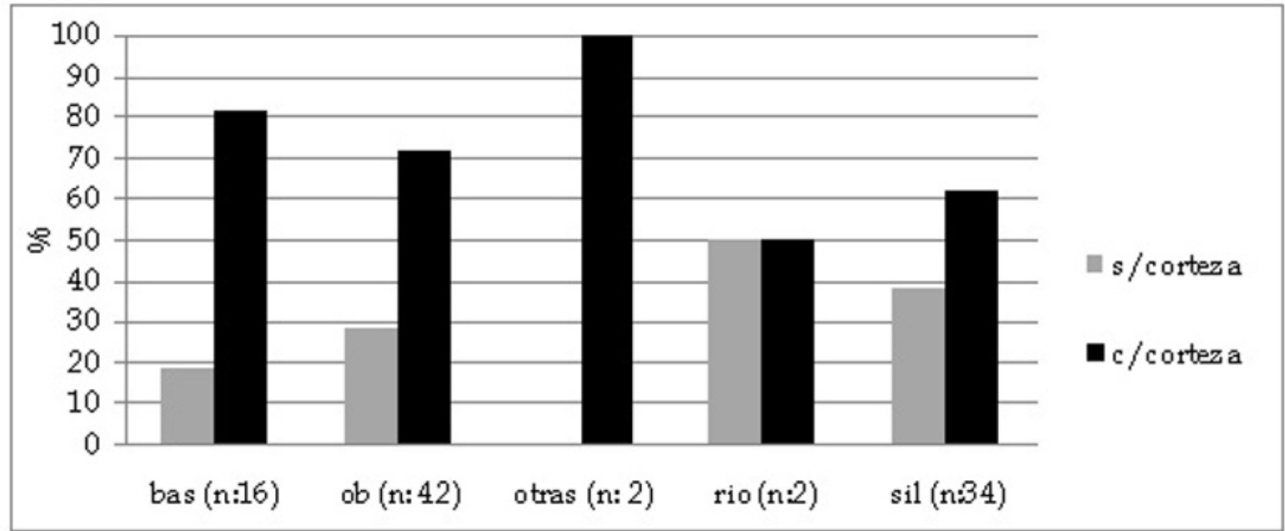

Figura 12. Corteza en núcleos enteros. Referencias: bas.: basalto, ob.: obsidiana, rio.: riolita, sil.: sílice

Para evaluar el tamaño de los núcleos enteros se estableció la media geométrica considerando el largo, ancho y espesor de los mismos (Figura 11). Se observa que la obsidiana se encuentra en tamaños menores que las rocas silíceas y el basalto/ andesita, estando estas últimas representadas en una mayor variedad de tamaños. Estas tendencias se vinculan con el tamaño en que se presentan las respectivas materias primas en los depósitos naturales (Espinosa 2002).

En todas las materias primas la mayoría de los núcleos tienen corteza, con valores que superan el 50\% (Figura 12). El mayor porcentaje de núcleos sin corteza corresponde a las rocas silíceas $(38,24 \%)$. 
La presencia de núcleos en los conjuntos da pautas específicas relacionadas con la utilización del espacio y, en consecuencia, con la movilidad de los grupos. En este sentido, resulta significativo no sólo que se encuentren en la mayoría de los conjuntos de la cuenca del lago Salitroso, sino también la alta representación de núcleos en materias primas que no están disponibles en la cuenca, obsidiana y ciertas variedades de sílice.

\section{Discusión}

El objetivo general de este trabajo ha sido establecer las características del aprovisionamiento y utilización de las materias primas líticas en la cuenca del lago Salitroso, manejando como hipótesis que las características de los conjuntos tecnológicos estarán condicionadas por el carácter residencial y la mayor duración de las ocupaciones en las cuencas lacustres bajas, en un contexto de reducción de la movilidad durante el Holoceno tardío.

\section{Aprovisionamiento de materias primas}

En una escala regional, existe disponibilidad de recursos líticos por lo cual es esperable que el aprovisionamiento de los mismos por los grupos humanos sea directo y que esté incluido dentro de otras actividades de subsistencia, minimizando los costos de obtención y búsqueda (Binford 1979).

Dado que Pampa del Asador constituye la única fuente regional de abastecimiento de obsidiana negra, la cual tiene propiedades óptimas para la talla y beneficios para la manufactura de artefactos formatizados como las puntas de proyectil, consideramos que los movimientos logísticos realizados hacia este espacio estarían focalizados en la obtención de esta materia prima. La representación de obsidiana en un 50\% de la producción lítica total del lago Salitroso y de una tendencia similar registrada en el PNPM (Espinosa 2002) podría dar cuenta de ello. Por otro lado, el hecho que casi un $40 \%$ de los núcleos de la cuenca del lago Salitroso sean de obsidiana y que un $25 \%$ de los desechos de esta materia prima sean primarios señala que dicha entrada a la cuenca se realiza mediante guijarros enteros o núcleos parcialmente descortezados. A su vez, Pampa del Asador no sólo ofrece materias primas de excelente calidad para la talla sino también muy buenas posibilidades para la obtención de recursos faunísticos, por lo cual la adquisición de ambos tipos de recursos estaría necesariamente relacionada. Asimismo, dada la mayor frecuencia de obsidiana en los conjuntos tardíos de sitios estratificados de la cuenca del lago Posadas (Guráieb 2000), su alta representación en las concentraciones de superficie del lago Salitroso y la existencia de estructuras de piedra utilizadas para la obtención de recursos faunísticos (parapetos) en Pampa del Asador para estos momentos (Goñi 2000-2002), consideramos que la interrelación entre ambas actividades se fortalecería hacia el Holoceno tardío, señalando un mayor uso de este espacio mesetario. En este sentido, pensamos que la distancia a la fuente de aprovisionamiento no sería un limitante o condicionante al momento de abastecer de obsidiana la cuenca, no así la disponibilidad estacional de Pampa del Asador. La importante carga de nieve que presenta durante los meses invernales esta meseta puede afectar las posibilidades de acceder a la misma. Durante estos meses puede entrar en juego en los circuitos de movilidad los sectores que se encuentran hacia el este de esta pampa ubicados en una menor cota altitudinal y con disponibilidad de nódulos de menor tamaño de obsidiana negra (Belardi et al. 2006). 
Con respecto a las rocas silíceas, existen distintas fuentes potenciales de abastecimiento por lo cual puede haber variabilidad en las estrategias de aprovisionamiento implementadas. Así, dado que en Pampa del Asador también se han registrado guijarros de muy buena calidad, consideramos que parte de las estrategias para su obtención se vinculan con las de la obsidiana. Al respecto se encuentran similitudes entre ambas materias primas en los conjuntos del lago Salitroso como las frecuencias de artefactos formatizados, la representación de lascas internas y la frecuencia y tamaño de núcleos. A su vez, los porcentajes menores de lascas externas y la mayor proporción de artefactos formatizados en comparación con la obsidiana permiten plantear la posibilidad de que algunos de los mismos ingresen parcialmente manufacturados a la cuenca. Es así que, una parte de las estrategias de aprovisionamiento de rocas silíceas puede estar en relación con un acceso indirecto o más distante de este recurso. En este sentido, no debe descartarse la posibilidad de la entrada de rocas silíceas de buena calidad desde sectores al este de la cuenca como la laguna Los Cisnes, a unos 75 km, (Aschero et al. 2010) y el Macizo Central del Deseado, localizado en promedio a unos $150 \mathrm{~km}$ lineales (Hermo 2009; Paunero et al. 2007). Resta poder diferenciar las distintas variedades de rocas silíceas y sus respectivas fuentes de aprovisionamiento para poder dar cuenta de la variabilidad de estrategias vinculadas con esta materia prima.

En relación con el basalto Posadas o andesita, materia prima disponible en la cuenca, la menor frecuencia de núcleos y el tamaño mayor de los desechos de talla pueden responder a la entrada de formas base a las concentraciones artefactuales del Salitroso, algunas de las cuales con corteza. A su vez, la ausencia en los conjuntos analizados de basaltos procedentes de Pampa del Asador marca el conocimiento de la base regional de recursos y una planificación en la utilización de la misma.

\section{Utilización de las materias primas}

En relación al manejo de las distintas materias primas pueden delinearse algunas tendencias. En primer lugar, la presencia de lascas externas y desechos de talla con tamaños medianos grande, grande y muy grande da pie a plantear, aunque en baja frecuencia, el desarrollo de tareas relacionadas con la extracción de formas base. La existencia de núcleos en la mayoría de las concentraciones artefactuales apoyaría esto. Por su parte, la alta frecuencia de lascas internas junto con el alto porcentaje de tamaños menores al módulo mediano pequeño estaría en relación con tareas de formatización, regularización y mantenimiento de instrumentos líticos. Es así que, la variabilidad en los tipos morfológicos y los tamaños de los desechos de talla junto con la alta frecuencia de núcleos permite establecer que todas las etapas del proceso de manufactura de artefactos están representadas en las concentraciones artefactuales de la cuenca.

En mayor o menor medida, estas tareas se estarían realizando tanto en la obsidiana como en las rocas silíceas y el basalto/ andesita. No obstante, se han registrado algunas diferencias entre las materias primas. La obsidiana y las rocas silíceas tienen similitudes con respecto a las características de los tamaños de desechos de talla y la frecuencia de núcleos $\mathrm{y}$ artefactos formatizados. Esto lleva a proponer que gran parte del proceso de manufactura de los artefactos de estas materias primas se habría desarrollado en la cuenca. A su vez, a diferencia de las rocas silíceas, la mayor representación de lascas externas en obsidiana da cuenta del traslado de guijarros enteros o parcialmente descortezados a las concentraciones. Por su parte, como fue mencionado anteriormente, el basalto Posadas o andesita entraría 
como formas base a las concentraciones artefactuales del Salitroso. En este sentido, es relevante la información aportada por las investigaciones realizadas en el sitio Cerro de los Indios 1 - ubicado a unos $10 \mathrm{~km}$ del lago Salitroso- ya que proponen que el mismo habría funcionado como un aprovisionador de formas base de esta materia prima (Guráieb 1998, 2012; Tívoli 2005). De esta manera, el proceso de producción de los artefactos de basalto se desarrollaría en distintos sectores de la cuenca de los lagos Salitroso- Posadas- Pueyrredón. Esta diferencia entre las materias primas puede responder a la manera en que se presentan en los depósitos naturales, ya que el basalto lo hace en forma de bloques y no guijarros transportables como la obsidiana y las rocas silíceas.

El desarrollo de este amplio rango de actividades de producción lítica sería esperable en sectores ocupados por tiempos prolongados que podrían estar funcionando como campamentos residenciales (Binford 1982; Kelly 1992). Lo planteado también se condice con la alta riqueza artefactual de varias de las concentraciones artefactuales analizadas (Cassiodoro 2010).

En segundo lugar, se ha registrado la selección de materias primas para la manufactura de determinados artefactos. Así, las puntas de proyectil predominan en obsidiana, las raederas en basalto y los raspadores en rocas silíceas. Es de destacar que este patrón ha sido reconocido en otros sectores de la región como el Parque Nacional Perito Moreno, el sitio Cerro de los Indios 1 y el lago Pueyrredón (Aschero et al. 2005; Bozzuto 2010; Guráieb 2000, 2012; Re 2006). Se plantea que el conocimiento de las actividades a realizar en cada uno de los espacios y la necesidad que se desarrollen de manera óptima va a requerir que las materias primas seleccionadas para la confección de cada una de las herramientas sean adecuadas a la función que llevarán adelante. Así, la selección de determinadas materias primas para la manufactura de artefactos específicos no sólo se relacionaría con la efectiva disponibilidad de recursos líticos (Guráieb 2012) sino también con este pautamiento o planificación de las actividades.

En función de las variables analizadas, con respecto al grado de utilización de las materias primas no se han establecido diferencias importantes entre ellas y, en términos generales, existe una ausencia de estrategias que busquen economizarlas. La ampliación de los rangos de acción a través de movimientos logísticos y la plena incorporación de Pampa del Asador a los circuitos de movilidad establece un flujo casi constante de materia prima lítica a la cuenca. Consideramos que si existen estrategias de maximización podrían estar vinculadas con las rocas silíceas, dadas la mayor frecuencia de artefactos fracturados, la menor frecuencia de desechos de talla y formas base con corteza y un mayor número de raspadores con filos complementarios. Esto lleva a la necesidad de ampliar las variables analizadas y especificar mejor las fuentes de aprovisionamiento de este recurso lítico.

Al mismo tiempo, se ha registrado variabilidad en la representación de las materias primas en artefactos formatizados, desechos de talla y núcleos en las diferentes concentraciones artefactuales de la cuenca. En trabajos anteriores, en función de la estructura y densidad artefactual, se ha dado cuenta de diferencias en el rango y tipo de actividades realizadas en cada una de ellas (Cassiodoro 2010). Teniendo en cuenta la selección de materias primas para diferentes clases artefactuales, consideramos que parte de dicha variabilidad podría estar afectando a la representación de materias primas en las concentraciones. Al mismo tiempo, la concentración de SAC 4 presenta algunas tendencias que la diferencian del resto 
de las concentraciones. En la misma predomina el basalto tanto en artefactos formatizados como en desechos de talla, hay una mayor representación de núcleos, los artefactos tienden a tamaños mayores y es el sector con mayor frecuencia de hojas, tanto como forma base de artefactos como en los desechos de talla (Cassiodoro 2008). Esta tendencia a la diferenciación tecnológica de SAC 4 del resto de las concentraciones es relevante ya que este sector se vincula con los fechados más tempranos ( $2.607 \pm 41$ años AP) de la cuenca del lago Salitroso (Goñi 2000-2002).

Finalmente, consideramos que la información aquí presentada puede aportar a la discusión sobre la relación entre la utilización de recursos minerales y los diferentes contextos en los cuales la movilidad se ve reducida (Andrefsky 2005; Parry y Kelly 1987; entre otros). Aunque aquí no se busca desarrollar dicha discusión si se espera delinear algunos aspectos que puedan contribuir a ella. En este sentido, distintos autores plantean que, cuanto mayor sea el tiempo de permanencia en un espacio, mayor será el grado de utilización de artefactos y materias primas que han sido transportadas al área (Kuhn 1995; Rolland y Dibble 1990; Veth 2005). También se ha propuesto un mayor uso de rocas locales y una menor diversidad de materias primas (Jones et al. 2003). Lo propuesto por estos autores no parece cumplirse plenamente en la cuenca en estudio. Es por ello que, es necesario considerar las características específicas de la base regional de recursos minerales del área (Andrefsky 1994) y las posibilidades de movimientos logísticos (Lurie 1989) en esta discusión. A su vez, no debe dejarse de lado que, las estrategias de producción de herramientas pueden ser influenciadas por una serie de factores que lleven a la toma de decisiones heterogéneas en las distintas poblaciones humanas (Andrefsky 2005).

\section{Consideraciones finales}

Este trabajó buscó establecer las características del aprovisionamiento y utilización de las materias primas líticas en la cuenca del lago Salitroso. Se ha registrado una planificación en las actividades relacionadas con el abastecimiento, uso y selección de recursos minerales necesarios para la producción de las diferentes tecnofacturas. En base a la información presentada, se ha propuesto que la variabilidad de materias primas utilizadas puede, en parte, estar en relación con las diferentes actividades desarrolladas en este espacio. Al mismo tiempo, otra parte de dicha variabilidad puede vincularse con el mayor número de movimientos logísticos efectuados en un contexto de movilidad residencial reducida (sensu Binford 2001). Esto disminuiría la incidencia de la distancia a la fuente de aprovisionamiento en la representación de materias primas de estos contextos. De esta manera, las estrategias de obtención de recursos líticos responderían a las particularidades de la estructuración de todos los recursos y de la utilización de los mismos. La implementación de estas estrategias para el aprovisionamiento de materias primas puede resultar en una utilización óptima del espacio en el marco de condiciones ambientales particulares del Holoceno tardío.

La información generada puede resultar un aporte a la discusión sobre la relación entre la utilización de recursos minerales y la mayor permanencia en un espacio de las poblaciones humanas. Así, un análisis de nuevas variables y la comparación de los patrones observados en la cuenca del Salitroso en una escala espacial y temporal mayor permitirán delinear en profundidad la utilización de los recursos líticos realizada por los grupos cazadores recolectores en el Holoceno tardío. 
Agradecimientos: A la Universidad de Buenos Aires, a Rafael Goñi y a todos los miembros del equipo que participaron en el relevamiento de campo. A la familia García de la Estancia Sierra Colorada, a Gabriela Guráieb y los pertinentes comentarios de los evaluadores. Las investigaciones fueron subsidiadas por la Secretaría de Cultura de la Nación y mediante distintos proyectos UBACyT (F064, F031, W0441) y CONICET (0122).

\section{Bibliografía citada}

Andrefsky, W.

1994 Raw material availability and the organization of technology. American Antiquity 59 (1): 21-34.

Andrefsky, W.

2005 Lithics. Macroscopic Approaches to Analysis. 2da. ed. Cambridge University Press, Cambridge

Aragone, A., Bourlot, T., Cassiodoro, G. y Re, A.

2004 Análisis comparativo del registro arqueológico en médanos del interior de Santa Cruz. Miradas. Trabajos de las V Jornadas de Jóvenes Investigadores en Ciencias Antropológicas (coord. por M. Carballido, C. Pisarello y A. Re), pp. 327-345. INAPL, Buenos Aires.

Aschero, C.

1975 Ensayo para una clasificación morfológica de los instrumentos líticos aplicada a estudios tipológico comparativos. Informe al CONICET. Ms en INAPL

1983 Ensayo para una clasificación morfológica de artefactos líticos aplicada a estudios tipológicos comparativos. Revisión. Cátedra de Ergología y Tecnología (FFyL-UBA). MS en INAPL

Aschero, C., R. Goñi, M. T. Civalero, R. Molinari, S. Espinosa; A. G. Guráieb y C. Bellelli. 2005 Holocenic Park: Arqueología del Parque Nacional Perito Moreno (PNPM). Anales de la Administración de Parques Nacionales XVII: 71-119.

Aschero, C., D. Bozzuto, T. Civalero, M. De Nigris, S. De Acha, N. Fernandez, L. González, L. Horta, A. Lacrouts, M. Sacchi y S. Tecce.

2010 Ocupaciones humanas en la costa norte del lago Pueyrredón y el área de laguna de Los Cisnes: avances en las investigaciones. Presentado en el XVII Congreso Nacional de Arqueología Argentina, Mendoza.

Bamforth, D.

1986 Technological efficiency and tool curation. American Antiquity 51:38-50

Belardi, J. B., P. Tiberi, C. Stern y A. Sunico

2006 Al este del Cerro Pampa: ampliación del área de disponibilidad de obsidiana de la Pampa del Asador (provincia de Santa Cruz). Intersecciones en Antropología 7: 27-36.

Bellelli C., G. Guráieb y J. García.

1985-1987 Propuesta para el análisis y procesamiento por computadora de desechos de talla lítica (DELCO-desechos computarizados). Arqueología Contemporánea 2(1):36-53. 
Binford, L.

1979 Organization and formation processes: looking at curated technology. Journal of Anthropological Research 35(3):255-273

1982 The archaeology of place. Journal of Anthropological Archaeology 1 (1):5-31

2001. Constructing Frames of Reference. University of California Press, Berkeley.

Bousman, C.

1993 Hunter-gatherer adaptations, economic risk and tool design. Lithic Techonology 18 (1/2):59-86.

Bozzuto, D.

2010 Análisis de conjuntos superficiales de artefactos líticos. Sector noreste de la cuenca del lago Pueyrredón-Cochrane (provincia de Santa Cruz, Argentina). Tesis doctoral inédita. Universidad de Buenos Aires.

Cassiodoro, G.

2008 Movilidad y uso del espacio de cazadores-recolectores del Holoceno tardío: estudio de la variabilidad del registro tecnológico en distintos ambientes del noroeste de la provincia de Santa Cruz. Tesis doctoral inédita. Universidad de Buenos Aires.

2010 Composición artefactual de los conjuntos de superficie de la cuenca del lago Salitroso (Santa Cruz). Revista Magallania 38 (1): 215-236.

Cassiodoro, G., A. Aragone y A. Re.

2004a Más allá de los chenques...Registro arqueológico de sitios a cielo abierto en la cuenca de los lagos Salitroso-Posadas-Pueyrredón. Contra Viento y Marea. Arqueología de Patagonia (comp. por T. Civalero, P. Fernández y G. Guráieb), pp. 325-338. INAPL-SAA, Buenos Aires.

Cassiodoro, G., G. Guráieb, A. Re y A. Tívoli.

2004b Distribución de recursos líticos en sitios de superficie de la cuenca de los lagos Pueyrredón-Posadas-Salitroso. Contra Viento y Marea. Arqueología de Patagonia (comp. por T. Civalero, P. Fernández y G. Guráieb), pp. 57-69. INAPL-SAA, Buenos Aires.

Cassiodoro, G. y S. García Guráieb

2009 Análisis del registro tecnológico y osteológico de los entierros humanos del Holoceno tardío del lago Salitroso (Santa Cruz). Arqueología de Patagonia: una mirada desde el último confin (ed. por M. Salemme, F. Santiago, M. Álvarez, E. Piana, M. Vázquez y E. Mansur), pp. 613-628. Editorial Utopías, Ushuaia.

Ericson, J.

1984. Toward the analysis of lithic reduction systems. Prehistoric Quarries and Lithic Producion (ed. por J. Ericson y B. Purdy), pp. 11-22. Cambridge University Press, Cambridge

Espinosa, S.

2002 Estrategias tecnológicas líticas y uso del espacio en momentos tardíos en el Parque Nacional Perito Moreno (Santa Cruz). Tesis doctoral inédita. Universidad de Buenos Aires.

Espinosa, S. y R. Goñi.

1999 Viven! Una fuente de obsidiana en la Pcia. de Santa Cruz. Soplando en el Viento. Actas de las III Jornadas de Arqueología de la Patagonia. pp. 177-188. Edición INAPL-UN de Comahue, Neuquén-Buenos Aires. 
García Guráieb S., P. González y V. Bernal.

2007a Estructura de sexo y edad de la muestra de restos humanos del Holoceno tardío del Lago Salitroso (Santa Cruz, Argentina). Arqueología de Fuego- Patagonia. Levantando piedras, desenterrando huesos...y develando arcanos (ed. por F. Morello, M. Martinic, A. Prieto y G. Bahamonde), pp. 367-374. CEQUA, Punta Arenas.

García Guráieb, S., R. Goñi y L. Bosio

2007b Lesiones traumáticas en un entierro del lago Salitroso (Santa Cruz, Argentina). Arqueología de Fuego- Patagonia. Levantando piedras, desenterrando huesos...y develando arcanos (ed. por F. Morello, M. Martinic, A. Prieto y G. Bahamonde), pp. 375-380. CEQUA, Punta Arenas.

Goñi, R.

2000 Arqueología de momentos históricos fuera de los centros de conquista y colonización: un análisis de caso en el sur de la Patagonia. Desde el País de los Gigantes. Perspectivas Arqueológicas en Patagonia. pp. 283-296. UNPA, Río Gallegos.

2000-2002 Fechados radiocarbónicos y registro arqueológico en la cuenca de los lagos Salitroso/Posadas (Santa Cruz). Cuadernos del Instituto Nacional de Antropología y Pensamiento Latinoamericano 19: 666-668.

2010 Cambio climático y poblamiento humano durante el Holoceno tardí en Patagonia Meridional. Una perspectiva arqueológica. Tesis doctoral inédita. Universidad de Buenos Aires.

Goñi, R., G. Barrientos y G. Cassiodoro.

2000-2002 Condiciones previas a la extinción de las poblaciones humanas del sur de Patagonia: una discusión a partir del análisis del registro arqueológico de la cuenca del lago Salitroso. Cuadernos del Instituto Nacional de Antropología y Pensamiento Latinoamericano 19: 249-266

Guráieb, G.

1998 Cuáles, cuánto y de dónde: tendencias temporales de selección de recursos líticos en Cerro de los Indios I (Lago Posadas, Santa Cruz). Arqueología 8:77-99.

2000 Diversidad artefactual y selección de recursos líticos en contextos tardíos de Cerro de los Indios 1 (lago Posadas, Santa Cruz). Desde el País de los Gigantes. Perspectivas arqueológicas en Patagonia. pp. 19-30. UNPA, Río Gallegos.

2012 Tendencias tecnológicas, selección de materias primas y diseño de artefactos líticos en la secuencia de ocupaciones del Holoceno tardío de Cerro de los Indios 1 (CI1), lago Posadas, provincia de Santa Cruz. Tesis doctoral inédita. Universidad de Buenos Aires.

Guráieb, G., G. Cassiodoro, A. Re y A. Tivoli.

2006 Distancia a la fuente de aprovisionamiento y variabilidad en los conjuntos líticos de la cuenca de los lagos Pueyrredón-Posadas-Salitroso (Patagonia cordillerana Argentina). Sociedades Prehistóricas, Recursos Abióticos y Territorio (ed. por G. Martínez Fernández, A. Morgado Rodríguez y J. Afonso Marrero), pp. 199-214. Fundación Al_Jatib de Estudios de Cooperación Cultural, Granada.

Hermo, D.

2009 Estructura de los recursos líticos y paisajes arqueológicos en el Nesocratón del Deseado (Santa Cruz, Argentina). Arqueología Sudamericana 5 (2): 178-203. 
Horta, L. y C. Aschero.

2010 Evidencias de un paleolago pleistoceno tardío-holoceno temprano en el área del lago Pueyrredón, noroeste de la provincia de Santa Cruz. Arqueología Argentina en el Bicentenario de la Revolución de Mayo, XVII Congreso Nacional de Arqueología Argentina (ed. por R. Bárcena y H. Chiavazza), pp. 1929-1934 Tomo V. UNCuyo-CONICET, Mendoza.

Jones, G., C. Beck, E. Jones y R. Hughes

2003 Lithic source use and paleoarchaic foraging territories in the Great Basin. American Antiquity 68(1): 5-38.

Kelly, R.

1992 Mobility/sedentism: concepts archaeological measures, and effects. Annual Reviews in Anthropology 21:43-66

Kuhn, S.

1995 Mousteriann Lithic Technology. An Ecological Perspective. Princeton University Press. Princeton, New York.

Lurie, $\mathrm{R}$.

1989 Lithic technology and mobility strategies: the Koster site Middle Archaic. Time, Energy and Stone Tools (ed. por R. Torrence), pp. 46-56. Cambridge University Press, Cambridge.

Nami, H.

1992 El subsistema tecnológico de la confección de instrumentos líticos y la explotación de los recursos del ambiente: una nueva vía de aproximación. Shincal 2:33-53

Nelson, $\mathrm{M}$.

1991 The study of technological organization. Archaeological Method and Theory 3:57-100. Parry, W. y R. Kelly

1987 Expedient Core Technology and Sedentism. The Organization of Core Technology (ed. por J. K. Johnson y C. A. Morrow), pp. 285-304. Boulder: Westview Press.

Paunero, R., A. Frank, F. Skabun, G. Rosales, M. Cueto, G. Zapata, M. Paunero, N. Lunazzi y $\mathrm{M}$ del Giogio.

2007 Investigaciones arqueológicas en sitio Casa del Minero 1, Meseta Central de Santa Cruz. Arqueología de Fuego- Patagonia. Levantando piedras, desenterrando huesos...y develando arcanos (ed. por F. Morello, M. Martinic, A. Prieto y G. Bahamonde), pp. 577-588 CEQUA, Punta Arenas.

$\mathrm{Re}, \mathrm{A}$.

2006 Uso del espacio en el oeste de la cuenca de los lagos Pueyrredón, Posadas y Salitroso (provincia de Santa Cruz): una aproximación tecnológica. Tesis de Licenciatura. Universidad de Buenos Aires.

Rolland, N. y H. Dibble.

1990 A new synthesis of middle paleolithic variability. American Antiquity 55(3):480-499. 
Stern, C.

1999 Black obsidian from central-south Patagonia; chemical characteristics, sources and regional distribution of artifacts. Soplando en el Viento. Actas de las III Jornadas de Arqueología de la Patagonia. pp. 221-234. Edición INAPL- UN del Comahue, Neuquén-Buenos Aires.

Stine, $\mathrm{S}$.

1994 Extreme and persistent drought in California and Patagonia during mediaeval time. Nature 369:546-549.

Stine, S. y M. Stine.

1990 A record from Lake Cardiel of Climate Change in Southern America. Nature 345(6277):705-708

Tívoli, A.

2005 Aprovechamiento de recursos líticos: la inserción regional de Cerro de los Indios 1 (Santa Cruz, Argentina). Relaciones de la Sociedad Argentina de Antropología XXX: 123-145.

Veth, P.

2005 Cycles of aridity and human mobility risk minimization among late Pleistocene foragers of the western desert, Australia. Desert Peoples. Archaeological Perspectives (ed. por P. Veth, M. Smith y P. Hiscock), pp. 100-115. Blakwell publishing, Hoboken. 